\title{
Controlled investigation of deaths from asthma in hospitals in the North East Thames region
}

\author{
J EASON, H L J MARKOWE
}

\begin{abstract}
One hundred and thirty deaths definitely or potentially due to asthma occurring in hospitals in the North East Thames region over one year were identified from death certificates and Hospital Activity Analysis records. Thirty five of these deaths were considered after independent assessment to have been directly due to asthma. Control patients who left hospital alive after acute asthma attacks were selected and matched with cases for sex, age, and hospital. Management was compared in the two groups. Inadequate monitoring, including failure to monitor arterial blood gas values, and inadequate use of nebulised $\beta$ agonists occurred significantly more often in fatal cases. Use of sedation, inadequate treatment with steroids, exposure to potentially toxic doses of aminophylline, and inadequate clinical assessment were more common in cases than controls, but not significantly so. Failure to institute artificial ventilation contributed to seven deaths. Assessors considered important defects in management to have occurred in $83 \%(29 / 35)$ of the cases and $40 \%(14 / 35)$ of the controls. Nevertheless, most of the hospital deaths (19/35) were considered not to have been preventable. Eight other deaths in the region were attributed to the complications of asthma or its treatment. Three of these were associated with gastrointestinal bleeding and one with perforation of a duodenal ulcer.

Before considering policies aimed at speeding admission to hospital of patients with acute attacks of asthma it is crucial that the general standard of hospital care offered to all patients with asthma should be improved.
\end{abstract}

Department of Anaesthesia, King's College Hospital, London SE5 9RS J EASON, FFARCS, MRCP, senior registrar

Department of Epidemiology, London School of Hygiene and Tropical Medicine, London WC1E 7HT

H L J MARKOWE, MB, MSC, lecturer

Correspondence to: Dr Eason.

\section{Introduction}

Deaths due to asthma have been increasing in recent years in England and Wales, ${ }^{1} 1972$ having been certified in $1985 .{ }^{2}$ That many of these deaths may be preventable ${ }^{3}$ has been the conclusion of various regional surveys. ${ }^{48}$ Poor patient education, ${ }^{568}$ rapid onset of attacks, ${ }^{6}$ underestimation of severity of the attack, ${ }^{48}$ and inadequate assessment, monitoring, and treatment of attacks ${ }^{578}$ have all been associated with these deaths but, apart from one study which included an unmatched comparison group 9 and a recent study from New Zealand, ${ }^{10}$ previous studies have lacked control groups.

It has been argued that if a patient with a severe asthma attack reaches hospital alive a fatal outcome can almost always be avoided. ${ }^{11}$ Yet from $14 \%{ }^{8}$ to $37 \%{ }^{5}$ of deaths certified as due to asthma occur in hospital. It may be that these deaths reflect poor hospital management. ${ }^{579}$ This study was designed to establish whether the management of fatal cases was worse than that of survivors and to estimate the proportion of hospital deaths that might have been prevented.

\section{Patients and methods}

Copies of all death certificates issued in the North East Thames region between 1 April 1982 and 31 March 1983 on which the words "asthma" or "asthmatic bronchitis" appeared and on which the underlying cause of death was stated as asthma, bronchitis, or emphysema (ICD (9th revision) codes 466, 491-3) were obtained from the Office of Population Censuses and Surveys. Any patients aged less than $\mathbf{4 5}$ for whom chronic bronchitis was given as the underlying cause of death were also studied. ${ }^{7}$ In addition, all patients identified by the regional Hospital Activity Analysis as having died in hospital with mention of asthma (ICD code 493) among their index diagnoses were investigated. Patients aged under 5 (three) were excluded.

Permission to study hospital case notes was sought (and obtained in all but one case) from the consultant in charge. The patient's general practitioner was contacted and practice records, when available, also examined. For each fatal case investigated a control patient who had been discharged from hospital alive after an acute asthma attack was identified. These patients were of the same sex and age (to within 10 years) and had been admitted to the same hospital with a Hospital Activity Analysis index diagnosis of asthma within the year preceding the death of the patient with whom they were matched. In six instances investigation of control patients identified in this way showed that the reason for their admission had not been acute asthma. When this occurred a new control was identified who satisfied 
this requirement. On occasions when Hospital Activity Analysis records contained more than one suitable patient the patient whose admission was closest in time to that of the fatal case was chosen. In three instances in which patients were elderly and had died in small hospitals age differences of 12 , 18 , and 28 years were accepted to maintain matching for time and place of death. In six cases death occurred in a small hospital and it was not possible to find an appropriately matched patient within the preceding year, so Hospital Activity Analysis data for the year before were also examined. In one case for which it still proved impossible to find a matching patient a hospital with a roughly equal number of beds was chosen and its Hospital Activity Analysis records scrutinised for a control. Controls were studied in exactly the same way as fatal cases.

Each fatal case occurring in hospital was assessed and categorised as $(a)$ definite death from asthma - that is, a convincing clinical history of an acute asthma attack leading to death in a patient with a history of reversible $(>20 \%)$ airways obstruction proved by objective measurement or in whom necropsy showed pulmonary hyperexpansion and mucous plugging; $(b)$ probable death from asthma - that is, asthma considered on the basis of available clinical evidence to be the most likely cause of death, but no confirmation by pulmonary function tests or necropsy; $(c)$ death associated with asthma - that is, death not directly due to asthma but related either to the stress of the attack itself or to the consequences of its treatment; $(d)$ death not due to asthma - that is, hospital death in a patient whose death certificate or Hospital Activity Analysis coding mentioned asthma but whose death was not considered to be due to asthma; $(e)$ inadequate information-that is, hospital death but records too sparse for assessment; or $(f)$ patient dead on arrival at hospital-that is, brought in dead or failed to respond to resuscitative efforts and certified dead within one hour of admission.

Patients with inadequate records $(10)$, those found to be dead on arrival at hospital (30), and those derived only from Hospital Activity Analysis sources in whom asthma was clearly not the underlying cause of death (32) were not investigated further. All other cases were referred to one of four independent assessors (chest physicians of consultant or senior registrar rank), who were unaware of the initial categorisation. In the event of disagreement between one of us (JE) and the independent assessor about categorisation (four occasions) case details were referred to a second assessor and the majority view prevailed.

The adequacy of initial assessment, investigation, monitoring, and treatment in matched case-control pairs was then assessed independently by $\mathrm{JE}$ and an assessor, making use of all available information. Avoidable factors which were agreed to have contributed to death (cases) or adversely affected the course of the illness (controls) were recorded. Decisions on adequacy of care were made on the basis of how management differed from what was considered to be clinically appropriate at each stage of the illness without regard to the subsequent course.

The significance of case-control differences was tested by McNemar's test for paired observations. ${ }^{12}$

\section{Results}

The 130 cases studied were categorised as follows: definite death from asthma, 23; probable death from asthma, 12; death associated with asthma, 8; death not due to asthma, 47; dead on arrival at hospital, 30 (in 25 of these cases asthma was given as the underlying cause of death on the death certificate); inadequate information, 10 . Table I gives the age and sex distribution of the 43 patients whose deaths were definitely or probably due to asthma or were associated with the disease.

Table II lists the adverse management factors in the 35 patients whose deaths were definitely or probably due to asthma and their controls. Taking into account each patient's clinical circumstances and the facilities known to exist in individual hospitals, assessors considered there to have been inadequate initial investigation in 21 of the 35 fatal cases and inadequate subsequent objective monitoring in 23. Corresponding figures for the controls were 14 and 13 cases, respectively. (Absolute figures for failure to
TABLE II-Comparison of hospital management of patients with deaths recorded as definitely or probably due to asthma $(n=35)$ and their matched controls

\begin{tabular}{|c|c|c|}
\hline & $\begin{array}{l}\text { No of } \\
\text { cases }\end{array}$ & $\begin{array}{l}\text { No of } \\
\text { controls }\end{array}$ \\
\hline \multicolumn{3}{|l|}{ Initial examination: } \\
\hline $\begin{array}{l}\text { Inadequate clinical assessment } \\
\text { Inadequate initial investigation }\end{array}$ & 13 & \\
\hline No peak expiratory flow measurement when indicated & & 8 \\
\hline No blood gas measurements when indicated & 16 & 11 \\
\hline No chest radiography when indicated & & 1 \\
\hline \multicolumn{3}{|l|}{ Monitoring: } \\
\hline $\begin{array}{l}\text { Inadequate monitoring } \\
\text { No peak expiratory flow measurements when indicated } \\
\text { No blood gas measurements when indicated }\end{array}$ & ${ }^{18^{23}}$ & $11^{13^{*}}$ \\
\hline \multicolumn{3}{|l|}{ Drug treatment: } \\
\hline Aminophylline dosage excessive & 14 & \\
\hline Steroid treatment inadequate & 12 & 4 \\
\hline$\beta$ Agonist treatment inadequate & 11 & \\
\hline Sedation given & 16 & \\
\hline \multicolumn{3}{|l|}{ Other: } \\
\hline Delay in instituting treatment & 3 & \\
\hline Severe dehydration/hypokalaemia uncorrected & 3 & \\
\hline Unwise patient transfer & 1 & \\
\hline $\begin{array}{l}\text { Precipitate discharge } \\
\text { Pand }\end{array}$ & 1 & \\
\hline
\end{tabular}

${ }^{\star} \mathrm{p}<0.05$ (McNemar's test for paired observations).

perform initial investigations, regardless of clinical indication or relevance, were: no peak expiratory flow rate measurement, 25 cases, 12 controls; no blood gas measurements, 23 cases, 27 controls. Corresponding figures for failure to perform any subsequent monitoring were: no peak expiratory flow rate measurement, 25 cases, eight controls; no blood gas measurements, 22 cases, 31 controls.) Failure to institute artificial ventilation was considered to have contributed directly to seven deaths. This is illustrated by the following case histories.

Case 1 -A woman in her $60 \mathrm{~s}$, a non-smoker with well documented asthma, failed to respond to intravenous steroids and aminophylline $(1 \cdot 75 \mathrm{~g} / 24 \mathrm{~h})$, which led to a decision to ventilate electively. Five hours after the entry in the notes detailing the reason for elective ventilation the patient was still awaiting intubation and transfer to the intensive care unit; she suffered a cardiac arrest (during or immediately before which she vomited and aspirated) and died.

Both assessors considered that the decision to ventilate had been correct and that the delay in its implementation had led to this patient's death. The combination of excessive doses of aminophylline, cardiac arrest, and aspiration of vomit was noted.

Case 2-A woman in her 60 s had a long history of proved asthma. The fatal attack was precipitated by atenolol $100 \mathrm{mg}$, prescribed for recently diagnosed hypertension. The acute episode began within hours of her taking the first tablet. This was a severe asthma attack and the notes documented a decision to ventilate electively. As in case 1 , however, implementation was delayed for five hours, at the end of which the patient sustained a fatal cardiac arrest.

Both assessors considered that the fatal outcome might have been prevented by the immediate implementation of the decision to ventilate.

Case 3-A woman in her 40s with a long history of chronic asthma had a respiratory arrest in the ambulance on the way to hospital. She was successfully resuscitated by the ambulance crew, and after $250 \mathrm{mg}$ aminophylline, $0.5 \mathrm{mg}$ adrenaline, and $340 \mathrm{mg}$ hydrocortisone had been given in the casualty department she was considered fit for transfer to a larger hospital. She deteriorated acutely in transit and suffered a second respiratory arrest. She did not have an intravenous infusion in place, nor was she accompanied by anyone able to intubate. On arrival at the second hospital she was cyanosed and convulsing. She was given oxygen, paraldehyde $10 \mathrm{mg}$ intramuscularly, and diazepam $12.5 \mathrm{mg}$ intravenously and an

\begin{tabular}{|c|c|c|c|c|c|c|}
\hline \multirow[t]{2}{*}{$\cdot$} & \multicolumn{2}{|r|}{ Male patients } & \multicolumn{2}{|r|}{ Female patients } & \multicolumn{2}{|r|}{ Total } \\
\hline & No & Mean age in years $(\mathrm{SD})$ & No & Mean age in years (SD) & No & Mean age in years (SD) \\
\hline $\begin{array}{l}\text { Patients classified as dead on arrival at hospital } \\
\text { Deaths after admission : }\end{array}$ & 11 & $38(22)$ & 16 & $50(18)$ & $27 t$ & $44(19)$ \\
\hline $\begin{array}{l}\text { Definite deaths from asthma } \\
\text { Probable deaths from asthma } \\
\text { Deaths associated with asthma }\end{array}$ & $\begin{array}{l}7 \\
5 \\
6\end{array}$ & $\begin{array}{l}53(21)[54(24)]^{\star} \\
77(10)[70(9)] \\
62(18)[63(16)]\end{array}$ & $\begin{array}{r}16 \\
7 \\
2\end{array}$ & $\begin{array}{l}62(18)[59(19)]^{\star} \\
66(11)[66(14)] \\
69(13)[70(3)]\end{array}$ & $\begin{array}{r}23 \\
12 \\
8\end{array}$ & $\begin{array}{l}59(19)[58(21)]^{\star} \\
71(12)[68(12)] \\
64(13)[65(14)]\end{array}$ \\
\hline
\end{tabular}

* Ages of controls given in square brackets.

t Three deaths in this category have been excluded as asthma was not considered to be the cause of death 
infusion of $0.8 \%$ chlormethiazole was begun, but she was not ventilated until several hours after her arrival. She died four days later, without regaining consciousness, while being ventilated in the intensive care unit.

Both assessors considered that the circumstances surrounding the transfer of this patient and her initial management on arrival at the second hospitaland, in particular, the unacceptable delay in initiating artificial ventilationhad directly contributed to her death.

Aminophylline or theophylline was given in 31 of the 35 fatal cases and to 29 of the 35 controls. Doses exceeding those recommended by Hendeles $e t$ $a l^{13}$ were more common in the cases than controls ( 14 versus seven). For this study inadequate steroid treatment was defined as less than $10 \mathrm{mg}$ prednisolone (or equivalent dose of other steroid preparation) in the last 24 hours of life (or the first 24 hours after admission in controls) and inadequate nebulised $\beta$ agonist treatment as less than $10 \mathrm{mg}$ nebulised salbutamol (or equivalent dose of other nebulised $\beta$ agonist) over the same period when either was considered by the assessors to have been clinically indicated. Undertreatment with each class of drug was commoner in cases than controls, significantly so in respect of inadequate use of nebulised $\beta$ agonist. (Absolute figures for absence of treatment, regardless of clinical indication or relevance, were: no oral or parenteral steroids, 10 cases, six controls; no nebulised $\beta$ agonist, 17 cases, four controls.)

Giving benzodiazepines, opioids, or chlormethiazole in the last hour of life was considered to have been an important contributory factor in the deaths of six patients. Sedatives were also given in 10 other fatal cases but were not considered to have had a direct causal role. Sedatives (10 mg intravenous diazepam in one case) had also been given to eight of the 35 controls. The following case histories illustrate the inappropriate use of sedation.

Case 4-A man in his 60 s suffered an acute asthma attack, for which he was given a rapid injection of $500 \mathrm{mg}$ aminophylline intravenously. Atrial fibrillation then began and was treated with verapamil $5 \mathrm{mg}$ and diazepam $10 \mathrm{mg}$ intravenously, immediately after which he had a cardiac arrest and died.

Both assessors concluded that death in this case was associated with intravenous sedation, though an adverse reaction to verapamil could not be excluded.

Case 5-A woman in her 20 s with a history of 22 previous admissions for acute asthma and who had documented nocturnal dipping was transferred to another ward. On the new ward the medical and nursing staff concluded that she was "very demanding and hyperventilating to get attention." It was decided to stop her usual nebulised salbutamol and substitute saline placebo and begin diazepam $5 \mathrm{mg}$ by mouth three times a day. The last entry in the nursing card index read " 0500 saline placebo given with apparently good effect. At 0655 became very distressed, hyperventilating again and insisting that a doctor be called. Nebulise given and she fell asleep while taking it. 0900 oral diazepam $5 \mathrm{mg}$ given. 0920 cardiorespiratory arrest." Peak flow monitoring had been stopped 24 hours before death.

Both assessors considered that the deliberate substitution of placebo, use of diazepam, and failure to monitor peak expiratory flow were avoidable factors leading to this patient's death.

Overall, the assessors considered that there were major defects in management and treatment in $83 \%(29 / 35)$ of the fatal cases and $40 \%(14 / 35)$ of the controls. Assessors also categorised the avoidability of each death. Of the 35 definite and probable deaths from asthma, 16 (46\%) were considered to have been potentially avoidable.

Table III gives details of the eight deaths categorised as associated with asthma. In five of these cases asthma was mentioned on the death certificate, though not as the underlying cause of death. The assessors considered that severe criticisms could be made of the management and treatment of seven of these cases and two of the controls. None of the deaths, however, was considered avoidable.

\section{Discussion}

Inadequate assessment, investigation, and monitoring of fatal asthma attacks has been noted in several reviews. ${ }^{578} \mathrm{It}$ is important to know whether poor management is confined to fatal cases or whether it reflects a generally poor standard of care of all patients with asthma. Use of a control group allows consideration of the fundamental question of whether those who die receive worse assessment, investigation, and treatment or whether they are simply untreatable or unlucky, or both. The need for a control group has been recognised ${ }^{14}$ but exactly how such a group should be formed remains problematic. ${ }^{7}$ In two studies including controls no attempt was made to match for hospital of admission or severity of disease. ${ }^{910}$ In our study matching by hospital was done because of the wide variation in facilities and treatment policies among hospitals. Of the 35 deaths from asthma presented here, 22 occurred in large general hospitals (all with accident and emergency departments), 12 in various other hospitals, and one in a specialist psychiatric hospital.

We did not match cases and controls for severity of the acute attack, as there is no generally agreed criterion of severity and attempts to match patients for arbitrarily selected criteria would have precluded investigation of their validity as predictors of mortality. Other work has suggested that such markers as pulse rate and pulsus paradoxus may not be reliable predictors of risk of death. ${ }^{15}$ Furthermore, in many patients with asthma the clinical measurements on which matching might be based were not performed, and to exclude such subjects would produce a misleading picture of standards of assessment and monitoring. In this study comparisons of pulse rate, clinical grade, ${ }^{16}$ and (when available) blood gas values showed patients with a fatal outcome to have been on average more ill than controls on admission. Nevertheless, in a substantial proportion of fatal cases the patients did not appear to be severely ill at the time of admission, though failure to assess and investigate these cases adequately may have led to underestimation of severity.

Details of patient management have been presented in two ways. Absolute numbers of investigations not performed and treatment not given provide general information relating to provision of care. Failure to perform initial investigations and subsequent monitoring occurred frequently in both cases and controls. Such data, however, are difficult to interpret, as there is failure to relate management to the individual circumstances of each patient. Comparison of the care of patients who died with that of controls is made difficult by the generally poorer condition of patients in the fatal group. Additional results are therefore presented in table II showing the assessors' opinions about the occurrence of inadequate care, account having been taken of individual circumstances including severity of the attack. For example, it was considered reasonable not to attempt peak expiratory flow measurement in a patient too ill to speak at the time of admission. The results presented confirm that deficient investigation was a feature of fatal cases of asthma and show that this was more common in cases than controls. Monitoring of the clinical course of the illness was also significantly worse in cases than controls, particularly the failure to monitor blood gas values.

Failure to institute artificial ventilation was considered to have led to seven deaths. In all cases enough time and adequate facilities were known to have been available; indeed, in two of the cases presented the decision to ventilate electively was documented in the notes but delays in excess of five hours in each case meant that the decision was

TABLE III-Deaths associated with asthma

\begin{tabular}{|c|c|c|c|}
\hline Sex & $\begin{array}{c}\text { Age } \\
\text { (years) }\end{array}$ & $\begin{array}{l}\text { Certified underlying } \\
\text { cause of death }\end{array}$ & Assessors' conclusion about cause of death \\
\hline $\mathbf{M}$ & 26 & Perforated duodenal ulcer & $\begin{array}{l}\text { Unsuspected duodenal ulcer in patient taking } \\
\text { high dose aminophylline and steroids for acute } \\
\text { asthma attack }\end{array}$ \\
\hline $\mathbf{M}$ & 73 & $\begin{array}{l}\text { Chronic bronchitis and } \\
\text { emphysema }\end{array}$ & $\begin{array}{l}\text { Gastrointestinal bleed occurring during acute } \\
\text { asthma attack. Surgeons declined to operate } \\
\text { because of respiratory state }\end{array}$ \\
\hline F & 79 & Cirrhosis & $\begin{array}{l}\text { Gastrointestinal bleed occurring during acute } \\
\text { asthma attack treated with high dose amino- } \\
\text { phylline and steroids. Necropsy showed } \\
\text { unsuspected portal cirrhosis but no varices: } \\
\text { "cause of bleed remains obscure" }\end{array}$ \\
\hline $\mathbf{M}$ & 74 & Gastric ulcer & $\begin{array}{l}\text { Gastrointestinal bleed from unsuspected gastric } \\
\text { ulcer during acute asthma attack }\end{array}$ \\
\hline $\mathbf{M}$ & 68 & Myocardial infarct & $\begin{array}{l}\text { Intractable ventricular fibrillation while taking } \\
\text { high dose aminophylline for acute asthma. No } \\
\text { necropsy }\end{array}$ \\
\hline M & 62 & Myocardial degeneration & $\begin{array}{l}\text { Acute arrhythmia during acute asthma attack. } \\
\text { No necropsy }\end{array}$ \\
\hline $\mathbf{F}$ & 60 & Haemorrhagic pancreatitis & $\begin{array}{l}\text { Pancreatitis in patient having ventilation for } \\
\text { asthma: taking high dose aminophylline and } \\
\text { steroids }\end{array}$ \\
\hline M & 68 & Ruptured splenic aneurysm & Ruptured aneurysm during acute asthma attack \\
\hline
\end{tabular}


pre-empted by the patient's death. Other studies of hospital deaths suggest that ventilation is attempted infrequently. ${ }^{57.9}$

High doses of aminophylline increase the risk of ventricular tachyarrhythmias. Toxicity may be increased in patients who are already hypoxic, hypercarbic, hypokalaemic, or receiving $\beta$ agonists, ${ }^{17}$ erythromycin, ${ }^{18}$ or cimetidine ${ }^{19}$ (but not ranitidine ${ }^{20}$ ). Calculating aminophylline dosage according to the criteria suggested by Hendeles $e t a l,{ }^{13}$ we found that excessive doses had been given in more of the fatal cases (14) than controls (seven). Five of the 14 patients with a fatal outcome who received excessive aminophylline were known to have been having maintenance treatment with oral or rectal theophylline before admission (as were three of the seven controls in this category). Serum theophylline concentrations were measured in two controls but in none of the fatal cases. Clearly recommendations concerning the administration of aminophylline ${ }^{21}$ had been widely ignored.

Two of the definite deaths from asthma were associated with aspiration of vomit. Both patients had received excessive aminophylline. In two further cases the fatal episode was precipitated by aspiration of vomit during or after general anaesthesia. (Three patients among the 25 who were dead on arrival at hospital and whose death certificates gave asthma as the underlying cause of death had also inhaled vomit.) In the presence of tachypnoea we surmise that glottic closure may be ineffective and even minor aspiration may provoke catastrophic bronchoconstriction in hyperreactive airways.

Sixteen $(46 \%)$ of the patients with a fatal outcome and $8(23 \%)$ of the controls had been given sedatives in hospital. Though this is an improvement on the $70 \%$ reported by Cochrane and Clark, ${ }^{9}$ it is disappointing that sedating patients with acute asthma remains widespread. The distress shown by these patients may seem to invite sedation, but the risks are well known and sedation must be strongly discouraged.

Inadequate treatment with both $\beta$ agonists (significantly) and steroids (non-significantly) was more common in fatal cases than controls. Underuse of steroids ${ }^{5922}$ and intravenous or nebulised bronchodilators ${ }^{7}$ has been identified before.

In three of the eight deaths categorised as associated with asthma there was no mention of asthma on the death certificate. This is an important group to study in the context of adverse treatment effects which might otherwise be missed. The frequency of gastrointestinal bleeding was of particular interest. Collins-Williams et al reported one fatal gastrointestinal bleed among 30 deaths from asthma. ${ }^{23}$ In our study the haemorrhage was fatal in one case and probably contributed substantially to four further deaths, two of which were categorised as associated with asthma. Additionally, one patient whose death was in this category and one control suffered perforation of occult duodenal ulcers during their asthma attacks. There was also one case of acute pancreatitis. All these patients were receiving high dose steroid treatment, which in association with the stress of the illness may haye caused the gastrointestinal problems.

Of the 35 definite and probable deaths from asthma, 10 of the 16 $(63 \%)$ in subjects aged under 65 were considered to have been potentially avoidable, as were six of the $19(32 \%)$ in subjects aged 65 and over. Several surveys of deaths from asthma have excluded patients aged over 65 , which may have founded the belief that most, if not all, deaths from asthma can be prevented. ${ }^{3}$ The over $65 \mathrm{~s}$, however, contribute more than half of all certified deaths from asthma; in 1983, 51\% of all deaths from asthma in England and Wales occurred in this age group.

We conclude that though 16 of the 35 deaths (46\%) might have been prevented by better management in hospital, many were inevitable, in a few cases because the patients were moribund on admission (four) but usually because their disease had become chronic and intractable (15). Nevertheless, there is no room for complacency. Care in both fatal cases and the control group was often below generally accepted standards. Grouping all three categories of deaths from asthma together-that is, definite death from asthma, probable death from asthma, and death associated with asthma - the assessors considered serious defects in management to have occurred in $36(84 \%)$ of the 43 fatal cases and $16(37 \%)$ of the 43 controls.
Facilitated hospital admission ("open door" policy) may well be an important means of reducing the current mortality from asthma. ${ }^{15} 2425$ Units that have published results, however, are specialist units. Before recommending the widespread implementation of such a policy it is crucial that the general standard of hospital care offered to patients with asthma should be improved.

We acknowledge the generous help of the consultant medical staff and general practitioners in the North East Thames region who allowed their $\mathbb{D}$ patients' records to be examined. Thanks are due to Dr P Goldblatt, of the Office of Population Censuses and Surveys, and Messrs B Russell and R $\varrho$ Pooni, statisticians at the Hospital Activity Analysis Centre in Brentwood, for providing the information identifying fatal cases and controls. Assess- $\overrightarrow{\bar{\omega}}$ ment of cases and controls was by Dr Martyn Partridge, of Whipps Cross Hospital, London; Dr Andrew Miller, Mayday Hospital, Croydon; Dr David Blainey, St Bartholomew's Hospital, London; and Dr Colm Lanigan, department of thoracic medicine, King's College Hospital, London, without whose help the study could not have been completed. Professor Geoffrey Rose and Dr Valerie Beral, of the London School of Hygiene and Tropical \& Medicine, and Dr Gillian Hanson, Whipps Cross Hospital, gave advice, criticism, and encouragement throughout. We also thank Mrs Jean Snell, ? Mrs Margaret Fowler, Miss Gillian Unwin, Mrs Angela Turfit, Mrs Vera Barber, and Mrs Shelagh Levy for secretarial work and preparing the manuscript and Miss Bonita Peachey for advice and help in computing. JE is in receipt of a research grant from the North East Thames Regional Health Authority.

\section{References}

1 Office of Population Censuses and Surveys. Mortality statistics 1979-84. Ser DH2. Nos 6-11. London: HMSO, 1980-5.

2 Office of Population Censuses and Surveys. Mortality statistics 1985. Ser DH2 86/2. London: Government Statistical Service, 1986.

3 Anonymous. Fatal asthma [Editorial]. Lancet 1979;ii:337-8.

4 Fraser PM, Speizer FEL, Waters SDM, Doll R, Mann NM. The circumstances preceding death from asthma in young people in 1968 to $1969 . B r f D$ is $C$ hest 1971;65:71-84.

5 MacDonald JB, MacDonald ET, Seaton A, Williams DA. Asthma deaths in Cardiff 1963-74: 53 d) deaths in hospital. BrMed F 1976;i:721-3.

6 MacDonald JB, Seaton A, Williams DA. Asthma deaths in Cardiff 1963-74: 90 deaths outside $\vec{\bullet}$ hospital. BrMed f 1976;i:1493-5.

7 Ormerod LP, Stableforth DE. Asthma mortality in Birmingham 1975-7: 53 deaths. Br Med $\mathcal{J}$ 1980;280:687-90.

8 British Thoracic Association. Death from asthma in two regions of England. $\mathrm{Br}$ Med $\mathcal{J}$ 1982;285:1251-5.

9 Cochrane GM, Clark TJH. A survey of asthma mortality in patients between the ages of 35 and 64 in the Greater London hospitals in 1971. Thorax 1975;30:300-5.

10 Rea HR, Scragg R, Jackson R, Beaglehole R, Fenwick J, Sutherland DC. A case-control study of deaths from asthma. Thorax 1986;41:833-9.

11 Cooke NJ, Crompton GK, Grant WB. Observations on the management of acute bronchial asthma. Br $\mathcal{F}$ Dis Chest 1979;73:157-63.

12 Armitage P. Statistical methods in medical research. Oxford: Blackwell Scientific, 1971.

3 Hendeles L, Weinburger M, Bighley L. Disposition of theophylline after a single intravenous infusion of aminophylline. Am Rev Respir Dis 1978;118:97-103.

4 Stableforth DE. Death from asthma. Thorax 1983;38:801-5.

5 Hetzel MR, Clark TJH, Branthwaite MA. Asthma: analysis of sudden deaths and ventilatory arrests in hospital. BrMed f 1977; i:808-11.

16 Davis B, Gett PM, Sherwood Jones E. A service for the adult asthmatic. Thorax 1980;35:111-3. 7 Wilson JD, Sutherland DC, Thomas AC. Has the change to beta-agonists combined with orat theophylline increased cases of fatal asthma? Lancet $1981 ; i: 1235-7$.

18 Kozak PP, Cummins LH, Gillman SA. Administration of erythromycin to patients on theophylline. I Allergy Clin Immunol 1977;60:149-51.

9 Reitberg DP, Bernhard H, Schentag JJ. Alteration of theophylline clearance and half-life by cimetidine in normal volunteers. Ann Intern Med 1981;95:582-5.

20 Powell JR, Rogers JF, Wargin WA, Cross RE, Eshelman FM. Inhibition of theophylline clearance by cimetidine but not ranitidine. Arch Intern Med 1984;144:434-6.

21 Anonymous. Theophylline benefits and difficulties [Editorial]. Lancet 1983;ii:607-8. 22 Bateman JRM, Clarke SW. Sudden death in asthma. Thorax 1979;34:40-4. 1981;125:341-5.

24 Crompton GK, Grant IWB. Edinburgh asthma admission service. Br Med $\mathcal{F}$ 1975;iv:680-2.

25 Crompton GK, Grant IWB, Bloomfield P. Edinburgh emergency asthma admission service: report on 10 years' experience. Br Med f 1979;ii:1199-1201.

(Accepted 9 March 1987)

\section{Correction}

Maternal leucocyte zinc deficiency at start of third trimester as a predictor of fetal growth retardation

We regret that an error occurred in this paper by $\mathrm{J} \mathrm{L} \mathrm{Wells} \mathrm{and} \mathrm{others}$ (25 April, p 1054). In the bottom line of Table I all the values for median leucocyte zinc concentration are too small by a factor of 10 and should read $112 \cdot 0,150 \cdot 7,164 \cdot 2,192 \cdot 3,216 \cdot 0,229 \cdot 5$, and $165 \cdot 6$, respectively. 